\title{
ENTRE BRASIL E MÉXICO: ALFONSO REYES EN LOS ALBORES DEL ESTADO NUEVO BRASILEÑO (1930-1936), DE ALBERTO ENRÍQUEZ PEREA
}

Jacicarla Souza da Silva

\section{C67 ientras Brasil fue perfectamente feliz no tuvo historia" '. É a partir dessas palavras que integram a epígrafe do livro Alfonso Reyes en los albores del Estado Nuevo brasileño (1930-1936) ${ }^{2}$ que Alberto}

Enríquez Perea apresenta um valioso estudo que contempla não somente a trajetória do escritor mexicano Alfonso Reyes no Brasil, mas também resgata um importante momento da história e da cultura brasileira.

Embora represente uma figura de grande importância para a nossa cultura, o nome de Alfonso Reyes ainda parece configurar um desses ilustres desconhecidos entre nós brasileiros. A representatividade de sua obra pode ser comprovada pelo seu legado que reúne aproximadamente 26 tomos, os quais correspondem a 21 livros de versos, 88 de crítica, ensaio e memória, 7 de prosa, entre outros de teoria literária, totalizando 202 livros que foram publicados como títulos independentes. A estes números haveria que somar mais de 50 epistolários e 2 ou 3 volumes de escritos diplomáticos. ${ }^{3}$

Diante do clima tenso vivenciado pelo seu país no início do século XX, em decorrência das mudanças políticas ocasionadas pela Revolução Mexicana, em 1913 Alfonso Reyes viaja para a Europa, residindo em Paris, onde conhece muitos escritores e intelectuais da época.

No ano de 1915, ele passa a morar em Madrid, mantendo contato com importantes personalidades da cultura espanhola, tais como Miguel Unamuno, Valle-Inclán, Juan Ramón Jiménez, Menéndez Pidal, Ortega y Gasset e Azorín.

1 Trata-se de uma expressão presente no texto "Brasil es una castaña" de Alfonso Reyes, escrito em 24 de fevereiro de 1942.

2 ENRÍQUEZ PEREA, Alberto. Alfonso Reyes en los albores del Estado Nuevo brasileño (19301936). México-DF: El Colegio Nacional, 2009. xvi + 689p.

3 Dados apontados por MARTÍNEZ, José Luis. A obra de Alfonso Reyes. In: REYES, Alfonso. Alfonso Reyes Digital: obras completas y dos epistolarios. México: FCE, 2002. 1 CD-ROM 
Por intervenção de José Vasconcelos, nomeado Secretário da Educação do México em 1920, Alfonso Reyes retorna às atividades diplomáticas e em 1921 assume o cargo de primeiro secretário. Ele viaja a diferentes regióes da Europa representando seu país em vários cargos oficiais. Apesar de retornar esporadicamente ao México, é no ano de 1927 que ele volta definitivamente ao continente americano. Nesse mesmo ano, segue para Buenos Aires, não mais para o cargo de Ministro, mas sim de Embaixador, em que permanece até 1930.

Da capital argentina Reyes viaja ao Brasil com a missão de substituir Pascual Ortiz Rubio, que nesse momento ocupava a presidência do México. O trabalho de Enríquez Perea tem seu ponto de partida justamente nesse período, de 1930 a 1936, em que Alfonso permanece em terras brasileiras.

Com a proposta de mostrar outro perfil alfonsino, que vai além da imagem de um escritor confinado em sua torre de marfim, a obra Alfonso Reyes en los albores... traz à luz um Reyes "apaixonado pela política" ${ }^{4}$.

Para destacar essa outra faceta do autor de Visión de Anábuac, o livro estabelece um diálogo entre as diferentes produções de Reyes que vão desde suas anotaçóes em "Diário", correspondências particulares e diplomáticas a discursos, ensaios, entre outros textos. É a partir da leitura atenta que entrelaça todos esses significativos documentos que Alfonso Reyes en los albores... resgata parte da história da política brasileira:

El interés se centra en Reyes como observador político, como escritor político, como un hombre que tenía sensibilidad, perspicacia y agudeza política capaz de dejar en los documentos diplomáticos no sólo una idea sino un panorama amplio y complejo de lo que fue el nacimiento del Estado nuevo brasileño. ${ }^{5}$

Diante dessa proposta, a obra, que se divide basicamente em duas partes, contextualiza primeiramente em "Entre la dictadura y Constitución” o período da "Revolução de 1930", que consistiu no golpe de estado em que Getúlio Vargas assume a chefia "provisória” do país dando fim à República Velha. Jun-

4 ENRÍQUEZ PEREA, Alberto, op. cit., p. 5.

5 Id., ibid., p. 9. 
tamente com a "Revolução de 30" são situados os movimentos revolucionário e contrarrevolucionário, bem como a instauração da Constituição de 34. Já em "De la Constitución a la dictadura" é ressaltado o quadro político dominado pelas instabilidades e inquietaçóes do governo getulino em relação à nova constituição, bem como em torno dos movimentos comunistas que aparecem em diferentes cidades brasileiras. Alfonso Reyes, como se sabe, não acompanhou o final do segundo período em que Vargas esteve frente à presidência da República, já que ele retorna à Argentina em junho de 1936. Entretanto, ao retornar ao Brasil em 1938, já se depara com o Estado Novo, implantado após um golpe de estado, que, conforme lembra Enríquez Perea, "se fue gestando en los años que estuvo como embajador de México."6

Ao comentar sobre o olhar crítico e perspicaz de Reyes sobre esse cenário político brasileiro, o estudo coloca em evidência a participação do embaixador mexicano nos diferentes ambientes culturais da época, destacando a sua relação com personalidades tanto europeias quanto latino-americanas, as quais integraram o seu círculo de amizade.

Alfonso Reyes en los albores ainda recorre a alguns projetos literários em que o autor de Cartones de Madrid participou. Como, por exemplo, a revista Índice, da qual fizeram parte escritores espanhóis como Pedro Salinas, Gerardo Diego, José Bergamín, Jorge Guillén, Federico García Lorca, Dámoso Alonso, entre outros. Além de Índice, Cuadernos del Plata também representa uma de suas grandes contribuiçóes, esta, porém, voltada ao contexto argentino. Como se sabe, Alfonso Reyes publicou uma significativa quantidade de textos sobre os escritores argentinos daquele momento como Borges, Bioy Casares, Ricardo Güiraldes, somente para citar alguns nomes. Ainda sobre a sua estreita relação com o ambiente intelectual da Argentina, o livro traz à luz os bastidores de alguns trabalhos que não tiveram muito êxito, como o da revista Libra, em que Eduardo Mallea e Borges teriam se recusado em participar em discordância com os fundadores Bernárdez e Leopoldo Marechal.

No que se refere à estadia de Reyes no Brasil, o estudo ressalta a dedicação do embaixador mexicano em conhecer um pouco mais sobre a cultura local, assim como ocorreu em outros países por onde esteve, aproximando-se dos diferentes grupos de intelectuais e estreitando laços de amizades com

$6 \quad$ Ibidem, p. 14. 
várias personalidades. Prova disso foi a criaçáo do Pen Club brasileiro, com ajuda de seu amigo Ronald Carvalho.

Em terras brasileiras ele estabeleceu contatos com os mais diferentes grupos, desde intelectuais, professores e jornalistas a estudantes, adeptos de diferentes partidos políticos e vieses ideológicos. Dentro dessa diversificada rede de relaçōes, há nomes, por exemplo, como Rachel de Queiroz, Jorge de Lima, Prudente de Moraes, Carlos Lacerda, Gilberto Freyre, Jorge Amado, Cícero Dias, Di Cavalcanti, Graça Aranha, Sérgio Buarque de Hollanda, Ribeiro Couto, entre outros. No Brasil, ele dá início a grandes vínculos profissionais e de amizade, como ocorre com Cândido Portinari, Cecília Meireles e Manuel Bandeira, a quem Reyes ajuda a formular sua tese para apresentar no concurso para o posto de professor universitário na Universidade do Brasil ${ }^{7}$.

Ainda vale lembrar que no Brasil Reyes colocou em prática o audacioso projeto do correio literário Monterrey, escrito entre os anos de 1930 e 1937, durante sua permanência no Rio de Janeiro e em Buenos Aires. Monterrey, além de fortalecer os laços entre os intelectuais do continente americano, também foi um importante meio de divulgação do Brasil e de sua cultura, vista muitas vezes de maneira enigmática pelos países vizinhos.

Essa preocupaçáo em compreender a história, a política e a cultura brasileira está evidenciada nos textos presentes no anexo do livro, os quais mostram como Reyes transitava pelas diferentes áreas do conhecimento. A respeito desse material, lembra Enríquez Perea: "Las páginas que Reyes escribió sobre Brasil son de un hombre con una gran sensibilidad y perspicacia políticas fruto de sus reflexiones y de sus diálogos con los principales actores de la vida cultural, social, económica y política brasileña."

Esses escritos, cuidadosamente selecionados, apresentam um conteúdo bem diversificado que vai desde assuntos voltados à economia e à política até temas direcionados à questão da imigração, do turismo e do carnaval. Sem dúvida, eles revelam o conhecimento e o interesse do embaixador mexicano por esse país que o fascinava. O fato de colocar esses textos em circulação,

7 A orientação dada por Alfonso Reyes ao amigo brasileiro Manuel Bandeira para o concurso na Universidade do Brasil, que versou sobre a poetisa Soror Juana Inés de la Cruz, conforme destaca Alicia Reyes, está evidenciada na carta de junho de 1953. In: REYES, Alicia. Genio y figura de Alfonso Reyes. México: FCE, 2001. p. 202.

8 ENRÍQUEZ PEREA, Alberto, op. cit., p. 520. 
sem dúvida, representa outra grande contribuição desse trabalho tanto aos estudos alfonsinos quanto às pesquisas direcionadas à história e cultura latino-americanas.

Além de analisar o olhar perspicaz do escritor mexicano para as questóes políticas e sociais, a obra demonstra a consciência de Alfonso Reyes em registrar os acontecimentos e o cotidiano entre os diferentes lugares que passou. É nesse sentido que o autor do livro destaca que a incorporaçáo de Reyes ao serviço exterior foi um dos grandes acertos de sua vida.

Cabe ainda mencionar que o Rio de Janeiro passa a ser um ambiente de estímulo para a criaçấo de seus textos literários, influenciados pelo contato do escritor com a flora tropical que ele tanto admirava. ${ }^{9}$ Se, por um lado, a obra do autor mexicano não sairá ilesa desse processo de difusão cultural, por outro, o ambiente intelectual brasileiro não ficará incólume das "marcas do México". Tal premissa pode ser constatada ao longo do trabalho realizado por Enríquez Perea.

A estadia de Alfonso Reyes no Brasil, sem dúvida, serviu para intensificar o diálogo entre as Américas Hispânica e Lusitana, ressaltando, assim, as discussôes em torno da cooperação entre os países americanos, tema constantemente problematizado pelo escritor mexicano ao longo de sua obra.

Nesse sentido, pode-se afirmar que, mais que assuntos diplomáticos, Alfonso Reyes desempenhou um papel importante em relação ao diálogo entre as diversas expressōes literárias na América Latina.

Para o crítico uruguaio Ángel Rama ${ }^{10}$, pensar na aproximação entre culturas tão diversas representa uma tarefa desafiadora ou mesmo revolucionária. Segundo ele, estabelecer um paralelo entre as literaturas / culturas de língua portuguesa e espanhola na América equivale a uma aventura intelectual, a qual Rama considera fundamental para a compreensão do processo de transculturação no continente americano. É a partir dessa perspectiva, apontada

9 Sobre a presença das "marcas do Brasil" nos textos escritos de Alfonso Reyes durante a sua estadia no país, vale conferir o trabalho de Regina Crespo. In: CRESPO, Regina A. Cultura e política de Vasconcelos e Alfonso Reyes no Brasil (1922-1938). Revista Brasileira de História, São Paulo, 2 (45): 187-208, jul. 2003.

10 RAMA, Ángel. Algumas sugestôes de trabalho para uma aventura intelectual de integração. In: ROCCA, Pablo (Org.). Literatura, cultura e sociedade na América Latina. Belo Horizonte: Editora UFMG, 2008. p. 167. 
por Rama, que a obra de Enríquez Perea se perfila e contribui para pensar nas relaçôes culturais latino-americanas. Trata-se de uma aventura que mostra o amadurecimento de Reyes como escritor político e que perpassa pelas diferentes áreas do conhecimento. O livro ainda nos proporciona refletir, a partir de um olhar externo, um pouco mais sobre a nossa história. E como bem observou o escritor mexicano em "Brasil es una castaña": "La historia es la piedra que cae en el lago dormido. Esta intrusión no es necesariamente violenta". ${ }^{11}$

Recebido em: 28/03/12

Aprovado em: 28/11/12

${ }^{11}$ REYES, Alfonso. Brasil es una castańa. In: ENRÍQUEZ PEREA, Alberto, op. cit., p. 609. 